\title{
The banning of sportsmen and women who fail drug tests is unjustifiable
}

\author{
${ }^{1 S}$ Shuster, ${ }^{2} \mathrm{JW}$ Devine \\ ${ }^{1}$ Emeritus Professor of Dermatology, University of Newcastle upon Tyne, UK; ${ }^{2}$ Research Associate, The Ethox Centre, University of Oxford, UK
}

\begin{abstract}
The use of performance enhancing drugs among elite athletes has been in the headlines recently, particularly with Lance Armstrong's fall from grace and his admission about widespread doping. Many argue that the use of drugs confers an unfair advantage and is ultimately dangerous to the health of the athletes. Others, like Professor Shuster, argue that the use of drugs is no different from other techniques employed by athletes to boost their performance: swimmers shaving their body hair; skiers wearing sleek body armour; archers and shooters having laser eye surgery to improve their accuracy. Professor Shuster puts forward the provocative argument that since 'there is no acceptable proof (that) drugs improve competitive performance and their use is no different from accepted sports practice, banning them is wrong and immoral.' JW Devine argues the other side, that the use of performance enhancing drugs poses a 'significant risk to the health of athletes' and perhaps more importantly, 'threatens to undermine the very purpose of sport' by disrupting the 'balance of excellences'.
\end{abstract}

\author{
Correspondence to S Shuster, \\ 21 Lanyard Place, \\ Woodbridge IPI 2 IFE, UK \\ e-mail \\ sam@shuster.eclipse.co.uk
}

Correspondence to JW Devine,

The Ethox Centre,

Old Road Campus,

Oxford OX3 7LF, UK

e-mail

johnwilliam.devine@new.oxon.org

KEYWORDS World Anti-Doping Agency, erythropoietin (EPO), beta blockers, fairness in sport, pharmacological credibility, evidence-based medicine;

DECLARATION OF INTERESTS No conflicts of interest declared.

\section{Controversy about drugs in sport is more about a belief than reason}

\section{S Shuster}

How much of what we accept is based on thought and evidence, and how much on habit and fashion? The banning of athletes who fail drug tests in the absence of a logical or factual justification, gives an answer that makes a mockery of evidence-based medicine, and shows the 'controversy' about drugs in sport is more about belief than reason. ${ }^{1-3}$ My aim, therefore, is to move from belief to analysis - not to the soft option of debate: that provides more entertainment than resolution; indeed, a problem is 'debatable' only when the material necessary for its resolution is incomplete, and this, as I shall show, is not the case in the controversy about drugs and sport. A final introductory admission: I have always enjoyed sport (now sadly limited to timid tennis, safe skiing and rudimentary unicycling), but find much of athletic life and training, with or without drugs, excessive, dangerous and absurd.

The primary justification for banning drugs (see World AntiDoping Agency/International Olympic Committee codes and lists $^{4}$ ) is that they give unfair advantage by performance promotion (inhibitors are banned for horses but not yet not for jockeys!). But the underlying concept of fairness owes more to the correctness of the parental sports day dash than to elite competitive sport, which aims to outdo competitors by any means possible, short of detectable dishonesty. Fairness in sport? Think top tennis and how often a good ball is called out, and how rarely the player who benefits corrects the call. And where is the fairness in team cyclists' duty to 'neutralise' riders who attack their leader, or distance runners who box-in faster competitors? Exploiting weakness and error, not the philosophical definition of fairness, is sport's main concern. There is nothing 'fair' about natural, genetic superiority - few will ever play tennis as well as Federer, outrun Bolt, or outcycle Wiggins - which is why sport can't exist on the muddy level playing field of fairness. In that surreal looking-glass world we would only allow training in inverse proportion to innate ability; stage events at random (so synchronized swimmers could be running against weightlifters!); give performance enhancing drugs to potential losers, and inhibitors to winners, testing to ensure the drugs were taken regularly and banning when they weren't!

The confusion of 'cheating' (running in a walking race, fazing the signal from your foil) with 'unfair advantage' has no relevance to elite sport, which allows almost anything to gain an advantage - except drugs. Thus the absurdity of considering it fair to promote performance by training on mountain tops or in a low oxygen chamber, to increase red cell mass by erythropoietin (EPO), but cheatingly unfair to buy EPO to achieve the same end. 
It is argued that the use of drugs is unfair because they are taken secretly, ${ }^{5}$ but as the only reason for secrecy is the ban, and the personalised tricks of sports training are equally secret, the simple solution is to make both open. The belief that drugs are unfair because they are an external assistance whereas sport should be limited to an individual's own activity, ${ }^{5}$ has the chivalric irrelevance of a knight without armour. Training relies on specialised help and equipment; elite athletes employ teams of physiologists, psychologists and dieticians who treat foods, drinks and additives as drugs; cyclists ride specially designed bikes... the list could continue. So what makes the covert use of a stadium-load of performance-promoting specialists fair, and taking a pill cheating? Sports training and performance have nothing to do with fairness, and there is no logical or ethical difference in what competitors do to win a race with or without drugs.

So if the taking of drugs in itself gives no unfair advantage over other training procedures, what about performance promotion, the main case against them? Regrettably, the noisy concern about drugs in sport, and the intrusive testing industry it has sired, is about detection not effect; so the arguments offered are assumptions and none of the evidence is acceptable as proof. The naive pretence, offered as evidence, that sportspeople wouldn't use drugs if they were ineffective, ${ }^{5}$ ignores the placebo effect and the uncritical faith athletes have in specific foods, drinks, applications, the 'lucky' clothes and amulets they wear with embarrassed secrecy, and the great power of group fashion - the hope is that Bradley Wiggins' drugless success in the Tour de France starts a new one. Finally, the sad old 'revelations' about sports drugs in East Germany ${ }^{6}$ and their effect on female Olympians, are still replayed, Bayreuth fashion; but these are a powerful historical warning about state intervention, not evidence of pharmacological effect.

Of course, there is good experimental evidence of the effects of androgens, growth hormone, EPO ${ }^{7-9}$ and many other agents; the problem is its extrapolation. Thus, it is assumed that because androgens are anabolic for muscle they will promote performance of anything involving muscle; but as the requirements of the explosive 100 metres, the controlled distance run and the painful movement of a heavy weight are quite different, until suitable assay surrogates are found, proof of effect has to be the endpoint of winning. The $5 \%$ increase in running speed of recreational athletes given EPO or growth hormone $^{6}$ is not proof of effect, because dose response curves flatten at the top where Olympic champions reign (and for EPO in particular, because its concentration will already be increased by anoxic training, the only acceptable evidence is an additional effect following injection), but more importantly because it doesn't test the endpoint of competition outcome for elite competitors. Proof would need double-blind, randomised, placebo controlled studies of that endpoint for each different elite competition: it won't do to assume what promotes speed in the 100 metre dash will also provide a medal for walking, synchronised swimming or a tennis tie-break. Such studies have not been done for any of the banned sports drugs, ${ }^{4}$ and proof of a promoting effect has not been established. But could that effect be proved?

Because drug-taking is common but not universal, differences in outcome give a measure of possible promotional effect; and for Olympic medallists, for example, most time differences are $1 \%$ or less - very much less for some; more importantly, and with just two exceptions, the difference is the same for those subsequently disqualified for taking drugs. This trivial figure has no pharmacological credibility: apart from the massive study needed to establish it, $1 \%$ is just a mark at the end of a statistical dose-response curve, not a predictable effect in a single individual - and a less than $0.1 \%$ difference, which many medallists show, is just unrealistic as a pharmacological effect; indeed, there would be more justification for banning athletes who take homeopathic preparations. The belief that sports drugs are effective promoters has never been proved and never will be until a drug is found that produces an endpoint difference large enough for detection by simple studies.

Hard work and supreme skill won the Tour de France this year just as in previous years, regardless of whether or not drugs were used, and I cannot see the reason for disqualifying previous winners as cheats. Lance Armstrong has been a superb cyclist with the ability to outclass the many competitors who also took drugs but did not admit it; an irrational and outdated drugs code does not justify denigrating his achievements. Nevertheless, it is argued that the ban on drugs is appropriate because rules are rules - so if you don't like the rule on drugs in sport or the offside rule in football, play some other game. ${ }^{5}$ But a rule is not a justification; a rule can only justify itself by its purpose, not the circularity of its existence: the offside rule prevents unfair advantage, but, as we've seen, the banning of drugs does no such thing. The simple existence of rules on voting didn't justify the exclusion of citizens who happened to be women; it had to be changed, and so does the rule banning sports drugs. Perhaps it would help if the ban were tested in a court of law.

The World Anti-Doping Agency's justification for prohibiting drugs because of 'their potential to enhance performance' was restated recently by its President, who insisted that taking more blood tests was the only way to detect and control 'the cheats' who take them. ${ }^{10}$ Yet, following an article I wrote in the $B M J J^{3}$ a response was printed" agreeing my 'argument would have strength if the reason for banning were to ensure fairness of competition; but it is not. The principle behind drug 
control... is to prevent athletes from compromising their health for the sake of their sport'. Incredibly, this stands uncorrected, because the editors accepted its argument and refused my right of reply. But despite this editorial misreading of the rule book, which would wrongly ${ }^{12}$ make health the justification of testing and banning, who of sound mind would go along with this? Do drug deaths in pop stars justify testing before new albums are released and removal of golden discs afterwards? Should those caught smoking or taking other drugs at work lose their jobs for life, as do sportspeople? Does health give us the right to ban the obese from fishand-chip shops, and mountaineers because they regularly fall off mountains? The idea of testing and banning to protect health is totalitarian, disgusting and unacceptable, regardless of editorial opinion.

Since there is no acceptable proof drugs improve competitive performance and their use is no different from accepted sports practice, banning them is wrong and immoral; it should be stopped.We've acquired the biggest ever laboratories for sports drug testing; they should be used instead to improve our understanding of the effect of drugs on the delightful bodily function of sport.

\section{REFERENCES}

I Shuster S.The new sport of testing for sports drugs. In: Feldman S, Marks V, editors. Panic nation. London: John Blake; 2006.

2 Rushall B, Jones $M$. The anti-drugs-in-sport movement: causes for concern. Int J Sport Sci Coach 2006; I:I-16. http://dx.doi. org/I0.1260/I74795406776338445

3 Shuster S.Testing athletes, banning those who take drugs is unjustifiable. BMJ 20I2; 344:e352I. http://dx.doi.org/I0.I I36/bmj.e352I

4 World Anti-Doping Agency. List of prohibited substances and methods 2013 [Internet]. Montreal:WADA; 2013 [cited 2013 Jan 25]. Available from: http://list.wada-ama.org/

5 Rapid responses. Testing athletes, and banning those who take drugs, is unjustifiable. BMJ 20I2; 344:e352I. http://dx.doi.org/l0.1 I36/bmj. e352l

6 Franke WW, Berendonk B. Hormonal doping and androgenization of athletes: a secret program of the German Democratic Republic government. Clin Chem 1997; 43:1262-79.

7 Lippi G, Franchini M, Salvagno GL et al. Biochemistry, physiology, and complications of blood doping: facts and speculation. Crit Rev Clin Lab Sci 2006; 43:349-9I. http://dx.doi.org/I0.1080/I04083606007553 I3

8 McGrath JC, Cowan DA. Drugs in sport. Br J Pharmacol 2008; I54:493-5. http://dx.doi.org/ I0.1038/bjp.2008. I 7 I

9 Meinhardt U, Nelson AE, Hansen JL et al. The effects of growth hormone on body composition and physical performance in recreational athletes: a randomized trial. Ann Intern Med 2010; I52:568-77.

10 World Anti-Doping Agency. WADA President tells 10C more blood testing needed [Internet]. Montreal:WADA; 20I I [cited 2013 Jan 25]. Available from: http://www.wada-ama.org/en/Media-Center/ Archives/Articles/WADA-President-tells-IOC-more-bloodtesting-needed/

II Symonds J. Drug control in sports is about protecting athletes from exploitation. BMJ 20 I2; 344:e4 I43. http://dx.doi.org//0.1 I36/ bmj.e4I43

12 Fitch K. Proscribed drugs at the Olympic Games: permitted use and misuse (doping) by athletes. Clin Med 20I2; I2:257-60. http:// dx.doi.org/ | 0.786 I/clinmedicine. I2-3-257

\section{Doping is bad in sport because doping is bad for sport}

\section{JW Devine}

\section{INTRODUCTION}

In a year in which Chris Hoy cemented his place as an Olympic icon, Bradley Wiggins made history on the roads of France and Andy Murray became a Grand Slam champion, the sports story which perhaps had greatest impact beyond the back pages was Lance Armstrong's unseemly fall from seven-time Tour de France champion to serial drugs cheat.

On the face of it, Armstrong's story was nothing short of heroic: not satisfied with having overcome a nearfatal bout of testicular cancer, he returned to the saddle and achieved unrivaled dominance in one of sport's most gruelling contests. However, this apparent triumph was founded on the 'most sophisticated, professionalised, and successful doping programme that sport has ever seen'.' Armstrong ranks among the most prolific and high profile dopers in sporting history. Yet, his doping was not exposed by scientific evidence but by testimony against him, an investigation by the US Anti-Doping Agency and, finally, his own televised confession. Indeed, despite having been tested on approximately 200 occasions, he never failed a drugs test. This unsettling fact raises serious doubts about the drugs testing regime: are the testers so far behind the dopers that Armstrong could evade detection throughout his entire career, or were the authorities complicit in suppressing his failed tests?

A deeper question lies behind this story: should the use of performance enhancing drugs be banned in the first place? Is there anything wrong with doping other than it being against the rules? If not, then we could dispense with drug tests, banned lists and the whole anti-doping apparatus. We could lift the ban on doping and end the game of cat-and-mouse played out between dopers and testers. This libertarian picture is not without its attractions: no more tests, no more lies, no more cheats. So why not lift the ban?

The dangers of doping to the health of athletes and the fairness of competition are well known. As powerful as these arguments are, however, my principal objection to doping lies in the threat it poses to the very purpose of sport. 


\section{THE PURPOSE OF SPORT}

The rules of sporting competition limit what competitors may do in the pursuit of victory. Specifically, the rules preclude competitors from pursuing the ends of their sport in the most causally efficacious means possible. ${ }^{2}$ These limits are designed to ensure that victory is most reliably secured by the display of certain skills and capacities - 'excellences'. Runners must use only their legs to carry them, even though a bicycle would allow them to reach the line faster; high jumpers must jump from the ground to clear the bar, even though jumping from a trampoline would allow them to achieve greater heights; and boxers must use only their gloved fists to punch their opponent, even though a baseball bat would provide a much more efficient way of knocking them out. To call bicycles, trampolines or baseball bats 'enhancements' in these sports is a misnomer. Far from improving performance, their use would obscure the display of the relevant excellences (running, jumping and punching).

What follows from this excellence-based account of sport for the question of doping? I propose two different ways in which doping threatens to undermine the excellences around which sporting competition is organised: I) Doping can impede a relevant excellence from being displayed, thereby compromising the "clarity of excellence'; or 2) Doping can objectionably elevate some excellences over others, thereby disrupting the 'balance of excellence'.

\section{CLARITY OF EXCELLENCE}

If the rules of sport are designed to ensure that competitors display certain excellences, then no practice should be permitted which obscures or prevents the display of the excellence around which the sport is organised. $^{3}$

The four Grand Slam competitions in tennis ban the use of on-court coaches. Players are not permitted to bring a coach on court to advise them during their matches. This rule may in part be designed to prevent unfairness between those who can and those who cannot afford a professional coach to sit courtside. However, it can also be understood as an attempt to ensure that players display the excellences of mental fortitude and strategic nous. Players must cope on their own with the pressures and tactical challenges of competition. Once they step on court, there is no coach to calm their nerves, dictate their tactics or correct their errors. If coaches were allowed on court, it would be less clear how much a player's strategy was their own and whether their calm in the heat of competition was the result of their own mental fortitude or skillful counselling from an expert coach.
Applying this to the question of doping, consider the case of archery. Part of the difficulty of archery lies in overcoming both nerves and one's natural tremor to achieve perfect balance; an unsteady hand militates against pinpoint accuracy in the shot. Beta-blockers mask the physiological effects of anxiety and quieten one's natural tremor. This renders the task of accurate shooting considerably less difficult, because the archer no longer has to contend with the unwanted effects of an unsteady hand. Consequently, accurate shooting assisted by beta-blockers displays a narrower range of excellences than the same accurate shooting achieved without the use of beta-blockers. One of the reasons we admire world-class archers is their ability to achieve perfect accuracy by overcoming the physiological effects of nerves. Far from enhancing excellence, the use of beta-blockers precludes the display of an excellence that is central to the sport. ${ }^{4}$ In short, it obscures the clarity of excellence.

\section{BALANCE OF EXCELLENCE}

We design the rules of sport not only so that competitors must display certain excellences to some extent but also so that some excellences are more prominent than others. Not only is sport designed to call forth excellences of a certain kind, it is designed to call forth these excellences to a certain degree.

Tennis again provides an instructive example. ${ }^{5}$ Throughout the 1990s, with only the exception of Andre Agassi's victory in 1992, each winner of the men's championship at Wimbledon based their playing style around a dominant serve. This pattern attracted the criticism that tennis at Wimbledon had become 'one dimensional'. One excellence - powerful serving - had acquired undue importance in the way the game was played. In effect, excellence in serving became a sine qua non for success at Wimbledon. More importantly, the effect of dominant serving - points of only one or two shots precluded the display of other excellences, such as strategic nous, deftness of touch and patient point construction. In response to these criticisms, tennis authorities adjusted the speed of the court surface and the pressure of the balls to reduce the influence of powerful serving so that longer rallies and more strategic play would flourish. These measures are best understood as an attempt to redress the balance of excellence around which tennis is organised.

Twenty years on and the landscape of men's professional tennis has changed utterly. One of the primary drivers of this change has been the development of polyester strings, which allow players to impart on the ball a level of spin that was unheard of in the 1990s. Combined with improvements in racket technology and the slowing of playing surfaces, these changes have rendered it almost 
impossible for serve and volley players to succeed in the modern game. While John McEnroe, Boris Becker and Pete Sampras dominated the game in the $80 \mathrm{~s}$ and $90 \mathrm{~s}$ with powerful serves followed up by pinpoint volleys, hardly a single player in the present world top 100 bases their game style around approaching the net. The extreme spin that players like Rafael Nadal and Novak Djokovic can generate with their groundstrokes has made it very difficult to succeed at the net, thereby making the art of volleying practically extinct. This development has encouraged a different sort of 'one dimensional' player to that of the 1990s. The modern player is one-dimensional, not in relying on a dominant serve, but in relying on dominant groundstrokes. It may well be that the move towards longer rallies has gone too far, such that excellences in serving and volleying have now diminished in importance to an objectionable degree.This underlines that the debate over a sport's balance of excellence must be ongoing. There is never a 'once and for all' solution to the balance of excellence in sport. Our ideas of what purposes underpin a sport, and what undermines those purposes, are in continual development, as athletes find new ways to meet the challenge presented by the rules and manufacturers advance new equipment and technical aids.

Sport requires excellences of body, mind and spirit. However, doping tends to elevate only a narrow range of physical excellences; principally, speed, strength and stamina. If we assume that doping could significantly improve these capacities, then the small subset of excellences which stand to be enhanced by doping would assume new prominence at the expense of other excellences. In a sport like rugby, such a change would likely squeeze out small, skillful players like Shane Williams or Jason Robinson who specialise in evading the tackler using a low centre of gravity and crisp sidestep. While such players could still prove effective in attack, they could not hope to defend against the new giants of the doping era. Consequently, it is unlikely that they would be selected at the highest level and their

\section{REFERENCES}

I US Anti-Doping Agency. Statement from USADA CEO Travis T.Tygard regarding the U.S. Postal Service pro cycling team doping conspiracy [Internet]. Colorado: USADA; 2012 [cited 2013 Feb 8]. Available from: http://cyclinginvestigation.usada.org/

2 Suits B. The grasshopper: games, life and utopia. Peterborough: Broadview Press; 2005 [1978]. pp. 54-5.

3 Sandel M. The case against perfection. Cambridge, MA: Harvard University Press; 2007. Chapter 2. attacking genius would disappear from the rugby landscape. Rugby would descend to a battle of collisions between behemoths.

In tennis, we would again lose guile, touch and feel in favour of crash, bang, and wallop. Even if doping does not objectionably obscure the display of relevant excellences, it may alter to an objectionable degree the relationship between the various excellences that a sport is designed to call forth, that is, doping may upset the 'balance of excellence' that inheres in a sport.

One important implication of this view is that the banned list should not be uniform across all sports. Doping rules should be designed on a sport-by-sport basis, or at least in a way that is tailored to clusters of sports which test a similar set of excellences that may be affected by performance enhancing drugs. There is little value in imposing a ban on drugs that would improve an athlete's stamina in a sport that is entirely anaerobic.

\section{CONCLUSION}

In determining the rules regarding any kind of performance enhancing technology, we must chart a course between the two extremes of giddy libertarianism and rigid conservatism. The former risks opening the floodgates to change that would undermine the very purpose of the sport. The latter risks entrenching sport in a time warp, radically disconnected from innovation that could genuinely improve sporting performance without compromising its purpose.

In charting this course, we must keep at the forefront of our minds the risk that doping presents to the clarity and balance of excellence. Even if lifting the ban would eliminate one avenue by which cheaters gain an unfair advantage, we have sporting reason to maintain a ban on doping. Doping is bad in sport because doping is bad for sport.

4 Devine JW. Oxford debates: performance enhancing drugs should be allowed in sport. Opposer's opening statement [Internet]. Oxford University; 2010 [cited 2013 Feb 8]. Available from: http://www. ox.ac.uk/oxford_debates/past_debates/trinity_2010_drugs_in_ sport/index.html

5 Devine JW. Doping is a threat to sporting excellence. $\mathrm{Br} J$ Sports Med 20I I; 45:637-9. http://dx.doi.org/I0.II36/bjsm.2009.070862 